\title{
Figural after-effects, rate of "figure-ground" reversal, and field dependence
}

\author{
LUDWIG IMMERGLUCK ${ }^{1}$ \\ SAN FRANCISCO STATE COLLEGE
}

Field-independent Ss showed greater figural after-effects on a specific perceptual task and also higher reversal rates on a series of reversible figure tasks than did field-dependent Ss. The present data reveal a significant linkage between figural after-effect performance and diverse other perceptual response styles and suggest strongly, as did the results of a previously reported related study, that the elemental processes underlying these effects are related to broader and more complex behavior variables.

A recent study (Immergluck, 1966) brought to light a relationship between the magnitude of figural aftereffects and perceptual measures of field dependence. Briefly, it was shown that field-independent Ss exhibited such effects, while field-dependent Ss failed to demonstrate them on a specific perceptual task. It was hypothesized that whatever neural "trace" is left by the impact of a visual stimulus, it is a more potent one in independent Ss as contrasted with field-dependent ones in whom apparently the residual effects of an originally fixated visual stimulus are more readily obliterated by subsequently viewed new stimuli.

The present investigation seeks to relate both fielddependence and figural after-effect variables to still other perceptual response categories, more specifically, to tasks involving "reversible figures." The attempt to anchor figure-ground reversals to both measures of figural after-effects and field-dependence may become clear if one considers more closely the processes which are presumed to underlie such perceptual shifts. To begin with, alternating and momentarily competing cortical states have been offered (Hochberg, 1950; Vernon, 1954; Hebb, 1966) as the mediating mechanisms underlying figure-ground reversal, mechanisms in essence much akin to those purported to generate figural after-effects. The impact of the "figure" stimulus attribute satiates the pertinent cortical projection area, allowing the new (previously "ground") attribute to come into perceptual prominence, etc. Since the extent of such satiation is presumed to determine the strength of the after-effect, it is hypothesized that Ss who exhibit greater figural after-effect potency should also show a higher rate of figure-ground alternation on pertinent tasks, and, conversely, Ss in whom the impact of an externally presented stimulus leaves but a weak trace residue, should show low reversal amplitude.

But on a gross behavioral level figure-ground reversal implies also a perceptual ability to regard the same stimulus from diverse (or at least more than one) viewpoints. This attribute of perception is essentially not dissimilar to daily-life perceptual situations where a given stimulus environment may, like the reversible figure, contain more than one perceptual possibility and, as Hebb (1966) reminds us, responses to reversible figures represent but a sharpened example of ordinary perceiving. It is precisely the ability to make these kinds of perceptual shifts which invites comparison with measures of field dependence. More specifically, since measures of field dependence have been shown to assess the extent to which a $\mathrm{S}$ can either divorce himself from an immediate and momentary stimulus field or else is passively bound to it, it is presumed that fieldindependent Ss will exhibit higher rates of such perceptual shifts in reversible figure tasks than will field-dependent ones.

\section{Method}

The $\mathbf{S}$ groups, college students ranging in age from 19 to $22 \mathrm{yr}$,, were selected on the basis of their performance on a Rod and Frame Test similar to the one employed by Witkin (1954) and his associates. Briefly, the $S$ is confronted in an otherwise totally dark room by a luminous rod surrounded by a luminous square which can be tilted, independently of the rod, by the experimenter at various angles, and he is required to adjust the rod to what he considers to be its true vertical position while disregarding the various tilts of the frame. Typically, field-dependent Ss are swayed to a significantly greater extent by the surrounding tilted frame and make gross errors in their judged vertical position of the rod than do independent Ss who have presumably little difficulty in transcending the distracting influence of the frame and are consequently able to make very accurate judgments. For the present experiment, as in the previously reported study (ibid), Ss who were able to place the rod consistently within $3^{\circ}$ of its true vertical position were assigned to the field-independent group while those who showed a consistent deviation of $10^{\circ}$ or more were placed in the dependent group. By this method, the final S groups of 26 field-independent and 21 field-dependent were established.

All Ss were then exposed to a figural after-effect task identical to the one used previously and to three reversible figure tasks. In the former the I Figure consists of two different sized squares, one measuring 1 in., the other 1.5 in., separated equally by 2 in. from their respective centers to the central fixation point. Following a fixation time of $30 \mathrm{sec}$. the T Figure, consisting of two identical squares $1.5 \mathrm{in}$. was immediately 
Table 1. A Comparison Between Field-Independent and FieldDependent Subjects in Figural After-effect Performance*

\begin{tabular}{lrrr} 
& After-effect & No After-effect \\
\hline Field-Independent Subjects & 21 & & 5 \\
Field-Dependent Subjects & 6 & & 15 \\
& & $\begin{array}{l}x^{2}=12.94 \\
p<0.001\end{array}$ \\
\hline
\end{tabular}

* The "After-effect" column indicates the number of Ss who exhibited after-effects and the "No After-effect" column those Ss who did not demonstrate the effect.

presented and $\mathrm{S}$ was asked to identify the test squares as "equal" or "unequal." Presence of the after-effect is demonstrated by a $S$ 's perception of the test squares as "unequal." Three widely known ambiguous figures, Rubin's "Profile-Vase," Rubin's "Cross" (an octagon comprised of a black and a white "windmill" cross) and the commonly employed reversible perspective "Prism" (a small square within a large square connected at their corners by diagonal lines) were respectively utilized as the reversible figure tasks. Each figure was presented for a 2-min. interval during which S's number of reversal (indicated orally by $S$ ) was recorded.

\section{Results and Discussion}

Tables 1 and 2, comparing the performances on the figural after-effect task and the rates of figure-ground reversal for the field-independent and field-dependent groups reveals clearly significant differences $(p<.001)$ for the respective $S$ groups. The field-independent $S$ did not only demonstrate stronger figural after-effects (corroborating the previously reported study), but they also showed significantly higher reversal rates on all three reversible figure tasks than did the dependentSs. The consistency of this relationship is underscored by the great performance similarity on each of these

Table 2. The Rate of Reversal* on Reversible Figure Tasks for Field Independent and Field Dependent Subjects

\begin{tabular}{lcccccc} 
& \multicolumn{2}{c}{$\begin{array}{c}\text { Profile-Vase } \\
\text { High Low }\end{array}$} & \multicolumn{2}{c}{ Cross } & \multicolumn{2}{c}{ Prish Low } \\
High Low \\
\hline Field Independent Subjects & 22 & 4 & 20 & 6 & 21 & 5 \\
Field Dependent Subjects & 7 & 14 & 6 & 15 & 7 & 14 \\
& $x^{2}$ & 12.92 & $x^{2}=10.91$ & $x^{2}=7.17$ \\
& $p<0.001$ & $p<0.001$ & $p<0.01$ \\
\hline
\end{tabular}

* The "High" column indicates the number of $S S$ whose reversal rate was above the median reversal score for the pertinent reversible figure task, and the "Low" column the number of Ss whose reversal rate fell below the median score.
Table 3. The Rate of Reversal on Reversible Figure Tasks for Ss Who Showed Figural After-effects and Ss Who Showed No After-effects

\begin{tabular}{lcccccc} 
& $\begin{array}{c}\text { Profile-Vase } \\
\text { High Low }\end{array}$ & \multicolumn{2}{c}{$\begin{array}{c}\text { Cross } \\
\text { High Low }\end{array}$} & \multicolumn{2}{c}{$\begin{array}{c}\text { Prism } \\
\text { High Low }\end{array}$} \\
\hline After-effect & 22 & 4 & 21 & 5 & 19 & 7 \\
No After-effect & 6 & 15 & 5 & 16 & 4 & 17 \\
& $x^{2}=15.15$ & $x^{2}=15.24$ & $x^{2}=7.58$ \\
& $\mathrm{p}<0.001$ & $\mathrm{p}<0.001$ & $\mathrm{p}<0.01$ \\
\hline
\end{tabular}

tasks (cf., Table 2). Table 3, revealing the close relationship $(p<.001)$ between the magnitude of aftereffects and rate of reversal (again with a high degree of consistency between the respective reversal tasks) lends support to the contention that figure-ground reversal is based, at least in part, on neural satiation processes similar to those that generate after-effects.

The demonstrated relationship between figural aftereffects and diverse other perceptual response categories suggests once again that individual differences in the potency of a trace residue left by a previously fixated stimulus are significantly linked to other styles of perceiving and, beyond that, probably to broader and more complex behavior patterns. Indeed, the concept of field-dependence-independence itself, with all its attendant broader behavioral and personality implications, might possibly be more meaningfully understood once the details of the mechanisms by means of which the organism absorbs and processes environmental stimuli are brought to light. The data at hand suggest strongly that detailed explorations of figural aftereffects may well afford an opportunity to gain such understanding.

\section{References}

Hebb, D. O. A textbook of psychology. Philadelphia: Saunders, 1966. Pp. 270-271.

Hochberg, J. E. Figure-ground reversal as a function of visual satiation. J. exp. Psychol., 1950, 40, 682-686.

Immergluck, L. Visual figural after-effects and field dependence. Psychon. Sci., 1966, 4 (6), 219-220.

Vemon, M. D. A further study of visual perception. Cambridge: The University Press, 1954. P. 208.

Witkin, H. A., Lewis, H. B., Hertzman, M. Machover, K., Meissner, P. B., \& Wapner, S. Personality through perception. New York: Harper, 1954.

\section{Note}

1. This research was supported by a faculty research fund, San Francisco State College, under the auspices of a National Science Foundation Institutional Grant. 